\title{
BARRIERS TO IMPLEMENTING SOLAR ENERGY SYSTEMS IN BUILDINGS: THE RESIDENT'S PERSPECTIVE IN MALAYSIA
}

\author{
Laura Florez ${ }^{1}$ and Nurain Nabilah Ghazali ${ }^{2}$
}

\begin{abstract}
Fossil fuels, such as coal and natural gas are typically used to generate electricity. Fossil fuels are non-renewable resources and harmful to the environment as they release greenhouse gases when burned. With the increased demand of cleaner sources for electricity generation, renewable sources need to be adopted. In Malaysia, solar energy has been used in numerous industrial buildings as a source of electricity generation since the country benefits from high solar radiation throughout the year. However, solar energy is still not used in residential buildings despite a wide interest from the sector. This paper identified and assessed the barriers to implementing solar energy in residential buildings from the perspective of homeowners in Malaysia. Based on a literature search followed by a ranking and factor analysis of data from a questionnaire survey, key barriers were identified. Ninety-one responses from residents in Malaysia were obtained. The questionnaire results showed that the main barriers to adopting solar systems are financial limitations followed by limited solar suppliers in the region and lack of awareness of government incentives. The results of this study could be used to help suppliers and industrial stakeholders in understanding the major barriers and the government to put forward policies to promote solar systems for electricity generation in residential buildings.
\end{abstract}

\section{KEYWORDS}

Sustainability, process, safety/quality/health, renewable energy, residential energy systems

\section{INTRODUCTION}

Renewable energy has received increased interest in the residential building sector as a result of rising energy costs, environmental quality demands, and the potential for the sector to contribute to sustainable development. In Malaysia, the government has been developing an ambitious plan to implement sustainable energy solutions for residential buildings since residential users alone account for almost 7.5 million of total energy consumers (Abdullah et al. 2019). The plan is targeted towards reducing $45 \%$ of the greenhouse gas emissions and its dependency on non-renewable resources by 2030 , while

1 Lecturer in Construction Management, Bartlett School of Construction and Project Management, University College London, 1-19 Torrington Place, London, UK, WC1E7HB, 1.florez@ucl.ac.uk, orcid.org/0000-0002-9286-6949

2 Quantity Surveyor, Dhaya Maju Infrastructure (Asia) SDN-BHD, 10 Boulevard, 47400 Petaling Jaya, Selangor, Malaysia, nabilah2194@gmail.com, orcid.org/0000-0002-6911-0721 
ensuring the development of reliable and affordable energy sources (Muhammad-Sukki et al. 2011; Hossain et al. 2014). The execution of the Renewable Energy Act and the implementation of the Feed-in Tariff (FiT) in 2011 (Shafie 2011) followed by the Eleventh Malaysia plan (2016-2020) demonstrates the enormous efforts made in the country to employ renewable energy resources and become a more sustainable nation ( $\mathrm{Oh}$ 2018).

There are various renewable sources for electricity generation such as wind, biomass, and solar energy. Solar energy has the largest potential to become the main renewable energy source as opposed to other sources of electricity (Rahim and Hasanuzzaman 2013). The location of Malaysia (in the equatorial region) benefits all year long from a large amount of solar radiation due to its hot and sunny weather. With an estimated 400$600 \mathrm{MJ} / \mathrm{m}^{2}$ montly solar radiation (Mekhilef et al. 2011), Malaysa has a high potential for solar generation, specially in the Northern region.

Despite the abundance of solar radiation and the government's efforts, energy in Malaysia is still mostly produced by burning non-renewable resources and solar energy has not been widely develeoped (Chong et al. 2015; Abdullah et al. 2019). Around 20\% of electricity in industrial buildings is produced using solar energy. However, only about $2 \%$ of electricity in residential buildings is produced with solar energy because these are still underdeveloped in residential areas (Muhammad-Sukki et al. 2011). Residential users alone account for almost 7.5 million of total energy consumers in Malayisa (Abdullah et al. 2019), and an increase in the use of solar energy in this sector may reduce carbon emissions by $20 \%$ while eliminating the use of fossil fuels (Basri et al. 2015). These are key objectives for sustainable development.

The sustainable development goals (SDGs) are a global agenda with a vision to protect the planet (SDG 2020). In doing so, there are two goals specifically related to: 1) affordable and clean energy, and 2) sustainable communities and cities. These two goals emphasise the reduction of waste and an increase in efficiency with a whole life cycle perspective (SDG 2020). Reducing energy consumption and preserving the environment with alternative energy sources is one of the ultimate ways to reduce waste with a longterm impact. Reducing waste not only minimises resource depletion, but also adds value to users in the form of lower environmental impacts. These are the aims of sustainable development and to a broader extent Lean thinking (Huovila and Koskela, 1998). With the rising demand of electricity in residential areas due to the increase in household incomes, rapid electrification, and technology development (Hossain et al. 2014), the Malaysian government has been promoting the use of renewable sources of electricity generation. Why it has not been successful in residential areas, despite a wide interest from the sector?

This study will gather users' perspectives from the Northern region of Malaysia since it is of interest to determine what is stopping them from adopting solar energy despite the solar abundance in their region and the continuous efforts from the government to implement renewable sources of energy. In doing so, the underlying reasons that prevent the use of solar energy and their ranking can be understood, which could be used to help suppliers, industrial stakeholders, and the government to put forward policies to promote solar systems for electricity generation in residential buildings in Malaysia. 


\section{LITERATURE REVIEW}

\section{NON-RENEWABLE ENERGY SOURCES}

Electricity in Malaysia is generated from burning fossil fuels, predominantly oil, natural gas and coal. Malaysia is a net exporter of gas, but its natural gas reserves could last only 40 years (Samsudin et al. 2016), as gas production is declining by $10 \%$ each year due to the increasing extraction costs (Khor and Lalchand 2014). As sources of gas diminish, there has been an increase in the use of coal power plants and the government allows independent power producer (IPP) to generate electricity with coal supplies from Indonesia. It is expected that coal will source up to $63 \%$ of power in the next few years to overcome gas depletion and the rise of oil costs (Shafie et al. 2011; Chong et al. 2015). However, fossil fuels are rapidly depleting as demand for electricity increases, especially in residential areas (Kukreja 2015). Fossil fuels are non-renewable resources and release greenhouse gases, which are harmful to the environment and are one of the main sources of global warming (Al-Amin et al. 2009). Greenhouse gases such as sulphurous oxides cause acid rain and carbon dioxide causes climate change. Climate change leads to loss of food sources, floods, and temperature rises (Zainal 2016). The extraction of fossil fuels also negatively impacts land. Oil and gas extraction produce large amounts of waste and toxic water, while coal mining extraction create unusable and harmful land (Foo 2015). To minimize the environmental impact of non-renewable energy resources, the Malaysian government has been developing an ambitious plan to modify the current practices for electricity generation.

\section{RENEWABLE ENERGY SOURCES}

In 2001, the Malaysian government launched the Fifth Fuel Diversification Strategy to promote the development of renewable energy sources. This policy aimed to reduce dependence on crude oil and gas for generating electricity and mix these with other resources such as hydro, coal, and natural gas (Oh et al. 2010). In the long run, the strategy aimed to produce $5 \%$ of the electricity with renewable energy sources by 2010 . However, the energy mix proposed by the government also negatively impacted the environment (Al-Amin et al. 2009) as greenhouse gases were produced. The New Energy Policy 2010 was launched under the Tenth Malaysia Plan (2011-2015) and the Sustainable Energy Development Authority (SEDA) was created in 2011. SEDA functions as an administrator of issues related to Feed-in- Tariff (FiT), a program which offers long-term contracts to renewable energy producers (SEDA 2011; Azam 2014). With the FiT, the distribution licensee will pay the holders of renewable energy systems any excess of energy. This program reduces the monthly electricity bills as it is a long-term investment on the system. The Eleventh Malaysia plan (2016-2020) was developed to limit the dependency on fossil fuels while ensuring the development of affordable energy sources.

One of the priorities identified in the Eleventh Malaysia Plan and SEDA is to increase the use of renewable energy sources in the residential sector (Chong et al. 2015). With this priority, the government aims to achieve a $40 \%$ reduction in greenhouse gas emissions (Economic Planning Unit 2015). As of 2018, renewable energy sources only produced $6 \%$ of the total electricity. The government's target is for renewable energy sources to produce about $20 \%$ of electricity by 2025 and $35 \%$ by 2050 , respectively. There are several renewable energy sources available in Malaysia (Shafie et al. 2011). 


\section{Wind power}

Wind power is a renewable source and has a low cost. Wind is converted into electrical energy by wind turbines (Hassain 2014). However, the wind speed in Malaysia is relatively low (Samsudin et al. 2016), with an average speed between 1.5 and $4.5 \mathrm{~m} / \mathrm{s}$. Higher altitude areas can harness between 9 to $11 \mathrm{~m} / \mathrm{s}$ of wind power. Although this speed could suitably produce electricity through a low-speed wind turbine, wind speed fluctuates impacting the amount of power generated. Wind turbines can be noisy and large wind turbines need to be constructed to generate an equally large amount of electricity (Hassain et al. 2014). Government incentives are required at the initial stage of deployment of wind power since this is a capital-intensive investment (Abdallah, et al. 2019). The absence of wind power technology and low wind speeds impact the viability and broader use of wind power.

\section{Hydropower}

Hydropower is generated by converting the energy obtained from rain water into electricity. Hydro power plants are a reliable source of electricity that require a low generation cost. These systems are cost efficient and easily controlled, requiring a low operation and maintenance cost. The ideal criteria for using wind power generators are met in many areas of Malaysia. Hydropower electricity is cheaper compared to oil and coal, but requires high capital investment (Abdallah, et al. 2019). Additionally, the construction of dams destroy bio-ecosystems and hydro power plants can affect water flow and its quality.

\section{Solar photovoltaic systems}

Solar photovoltaic (PV) systems directly convert solar energy to electrical energy by means of semiconductors in photovoltaic cells (Kadir et al. 2010; Mekhilef et al. 2011). Residential solar panels can be installed on the rooftop, either stand-alone or gridconnected (Muhammad-Sukki et al. 2011) (Figure 1).
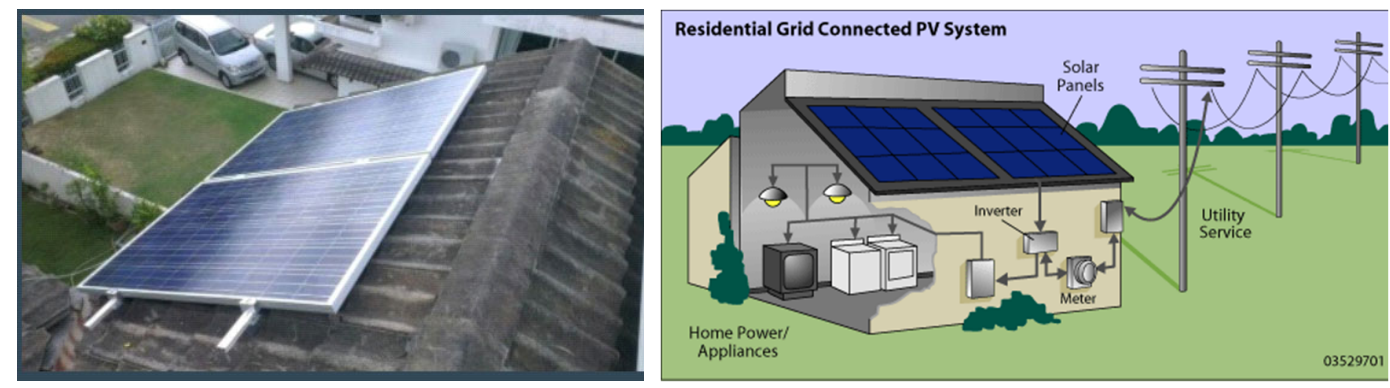

Figure 1: a) Roof layout of solar PV system and b) grid connected solar PV system (Taken from: (a) fitsolarplan.com and (b) SEDA 2014)

Solar photovoltaic (PV) systems have the largest potential as a renewable energy source in Malaysia due to the country's location benefiting from sunlight abundance (Rahim and Hasanuzzaman 2013). With a daily radiation of four to eight hours, the average annual irradiance is around $1,600 \mathrm{kWh} / \mathrm{m}^{2}$. Solar energy development was at $1 \mathrm{MW}$ as of 2011 , where it could potentially reach higher than 6,500 MW (Ahmad et al. 2011). Solar intensity is highest at the northern region and gradually decreases to the south, which makes the northern region of Malaysia an ideal location to invest in solar energy (Abdullah et al. 2019). 
Grid-connected PV systems are connected to the local utility grid. These PV systems produce electricity using solar energy and during cloudy days or at night (when there is no excess electricity) electricity can be obtained from the grid network. The excess energy can also be sold (under the FiT mechanism) to the electric distribution company. Solar PV systems have many advantages. The process of producing electricity is clean and noiseless since the technology does not require burning or physical conversion of the solar energy. According to Oh et al. (2010), $1 \mathrm{MW}$ of electricity produced by a solar PV system is equal to $4 \mathrm{MW}$ generated by conventional electricity. Because in a PV system electricity is produced in the place where it is needed, transmission losses can be avoided (Beccali et al. 2013).

\section{Barriers to using solar PV systems}

There have been several programmes launched by the Malaysian government to promote the use of solar PV systems in all sectors. The most well-known programme was the Malaysian Building Integrated Photovoltaic (BIPV) system in 2005 to promote solar PV systems (Mekhilef et al. 2011). However, in 2018 only $0.09 \mathrm{GW}$ solar energy systems had been installed, producing merely $0.1 \%$ of the electricity (Samsudin et al. 2016). Out of the installed systems, there were only 37 commercial users that had installed solar PV systems in their buildings (Chua and Oh 2012). Interestingly, the residential sector had expressed a higher desire in increasing the number of solar panels compared to the commercial sector (Shafie et al. 2011). Despite the interest, there are a number of barriers that prevent the implementation of solar PV systems for domestic use.

Cost is one of such barriers. The initial installation costs and sophisticated technology are believed to prevent residents from installing PV systems (Kamaruzzaman et al. 2012; Mekhilef et al. 2011). It was found that stakeholders believed they could not afford a PV system and $80 \%$ of the respondents agreed they would be interested in installing one if the government would fund half the cost. This study also found that the subsidies for PV technologies were lacking.

One more barrier highlighted in previous studies is public awareness. Gadenne et al. (2011) found that environmental actions are directly correlated to a person's knowledge on sustainable technologies. Muhammad-Sukki et al. (2011) found that Malaysian residents have limited knowledge and awareness of solar PV systems and the government programmes, including the advantages of installing solar panels and its long-term investment. Residents have the perception that renewable energy requires high investment costs and people are reluctant to shift to renewable energy because of the fear of change (Omar et al. 2013).

Another common barrier is the lack of suppliers to install and maintain solar PV systems. TS Solartech was the first local solar technology company, which made its first production line in 2012 (TS Solartech 2020). Prior to that, all solar PV components were imported from other countries such as Japan, which escalated the cost significantly (Kamaruzzaman et al. 2012). Gadenne et al. (2011) found that that the public demands a better range of manufacturers, which could maximize the product performance. Finally, the lack of government incentives prevents the use of solar PV systems. The existent government programmes do not have a high level of support to encourage users to shift to renewable energy (Fayaz et al. 2011). Renewable energy policies tend to be at the national level and local or regional policies are lacking. 


\section{RESEARCH METHODOLOGY}

This study adopted literature review and a questionnaire survey as its methods of data collection. A set of barriers was identified based on a thorough literature review of previous studies. The final list of 17 proposed factors hindering the use of solar PV systems formed the main content of the questionnaire design (Table 1).

\section{DATA COLLECTION}

A survey questionnaire was conducted in order to solicit opinions from Malaysian homeowners on the barriers for installing solar PV systems for domestic use. Homeowners included residents in the states of Perlis, Kedah, and Penang since the goal of the survey was to learn about the perceptions of domestic users in the Northern Region of Malaysia (a region with vast amount of solar energy). All of the respondents were at least 18 years of age and they all owned a house. Prior to distributing the survey, two respondents from each state completed a pilot survey to check for clarity and correct use of terminology. The recommendations from the pilot surveys were implemented to improve the readability of the survey questionnaire.

The survey questionnaire was composed of two parts. The first part was designed to collect basic information regarding the respondents' group age, monthly income, size of household, and type of dwelling. Additionally, respondents were asked whether they had installed a PV system in their homes and whether they were willing to change from conventional electricity to solar energy. In the second part, respondents were asked to evaluate the degree to which each factor was a barrier to using solar PV for electricity generation using a five-point Likert scale in which 1 represented "strongly disagree" and 5 represented "strongly agree." A number of questions to identify the level of knowledge on electricity generation and solar technologies in Malaysia were also included in part two. A snowball sampling technique was adopted to obtain a more effective and valid overall response, similar to the technique used in $\mathrm{Lu}$ and Yan (2007). This technique enabled the collection and sharing of a wide range of information through social networks to approach a wider associated population.

\section{Participants}

The initial respondents were selected using a residents' association database and readily available access via the co-author's employer. A total of 300 questionnaires were distributed via email. All questionnaires were sent to the respondents with a request for them to forward the questionnaire's link to other homeowners in their regions. Valid opinions were gathered using this approach to data collection. Out of the 300 questionnaires sent out, 91 were returned with valid responses, accounting for a response rate of $30.3 \%$. The minimum age of respondents was 18 years of age, $24.2 \%$ had 18 to 30 years, $26.4 \%$ had 31 to 40 years, $28.6 \%$ had 41 to 50 years, $15.4 \%$ had 51 to 60 years, and $5.4 \%$ had 61 years or older. Out of these respondents, $44(48.4 \%)$ were Kedah homeowners, followed by 40 (44\%) from Penang, and 7 (7.7\%) from Perlis. Note that the number of respondents from each region correlated with the population of each state. Figure 2 shows demographics of the population. Note that the average range of income was between RM 4,000 and 5,500. From all the 91 respondents, seven stated they had solar panels at home; three in each state of Penang and Kedah and one from Perlis. Six of these homeowners earned between RM 4,000 to 5,500 per month, while the other earned RM 2,500 to 4,000. Out of the seven who owned panels, two had 1-2 habitants in their households, while five had 3-6 habitants in their household. 

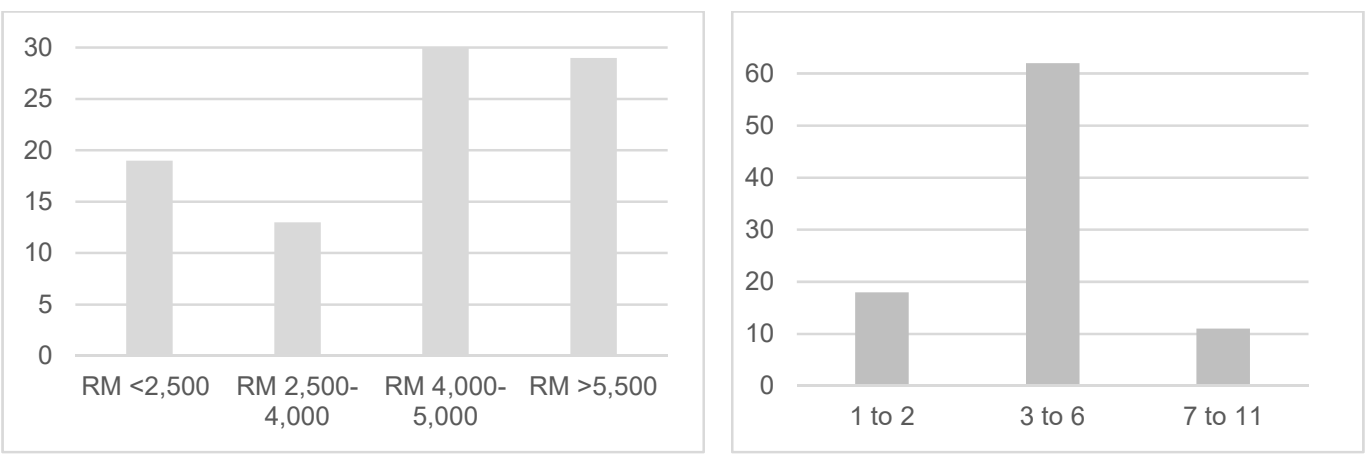

Figure 2: a) income of inhabitants in RM b) number of inhabitants per household

\section{Ranking analysis technique and factor analysis}

The mean score method was used to determine the relative ranking as perceived by the respondents in descending order of significance (Chan et al. 2003). If two or more factors happened to have the same mean score, the one with a lower standard deviation was assigned a higher rank. Cronbach's coefficient alpha was used to measure internal consistency among the various factors to evaluate the reliability of the five-point scale. The value of this study's test was 0.83 , which was higher than the 0.5 threshold, indicating that the five-point scale measurement was reliable at the 5\% significance level. Factor analysis (FA) was used to explore the underlying relationships among the critical barriers identified in this study. Prior to the application of this method, the Kaiser-Meyer-Olkin (KMO) measure and Bartlett's sphericity test were conducted. The KMO statistic varies between 0 and $1(0=\mathrm{FA}$ is appropriate and $1=\mathrm{FA}$ not appropriate) (Chan et al. 2003). Values greater than 0.5 indicate that the sample is acceptable for FA. All data analysis was performed using IBM SPSS version 24.0.

\section{RESULTS}

Table 1 shows the survey results. The majority of the respondents agreed that the "high initial purchase cost" is the main barrier to installing solar panels. Out of the 91 respondents, all of the 59 respondents with salary above RM 4000 were on agreement. Note that although these respondents have an income that is average or higher than average, they still perceived the costs to be hindering the use of solar panels for energy generation. The "high maintenance cost" ranked second, with also all the average to high earning respondents agreeing on this cost to be a barrier. Interestingly, the lowest ranked barrier was the "lack of awareness of solar panels", that is, most of the homeowners responded they have heard about solar panels, but $70 \%$ claimed that they very likely or likely didn't know any solar panels providers in their areas. For this reason, the third ranked barrier was "lack of solar panel providers" with more than $60 \%$ of respondents agreeing to this. The next most important barrier was "lack of experienced technicians for maintenance and support". Barriers ranked fifth and sixth show that respondents were unaware of the financial incentives provided by the government and the FiT. This contrasts with the findings of previous studies that claim the government programme was successful. These two barriers were closely related according to previous studies, as public awareness can be improved when encouraged by the government through different channels, such as policies, tax incentives, and financial support. 


\section{RESULTS OF RANKING ANALYSIS}

Factors with mean scores higher than the average total value (3.022) were identified as critical factors hindering the adoption of solar PV systems in Malaysia. The mean scores and ranking of the 17 factors are shown in Table 1. Table 1 also shows that 10 out of the initial 17 factors have mean scores greater than 3.022, and are therefore deemed critical factors. The first, as ranked by all respondents, is "high initial purchase cost" (mean = 3.88 and standard deviation (Std. dev.) $=1.078$ ), which is thus considered the greatest obstacle inhibiting the use of solar panels in the Northern region of Malaysia. "High maintenance cost" and "lack of providers of solar panels" are ranked second and third, respectively.

Table 1: Critical factors hindering the use of solar PV systems in Malaysia

\begin{tabular}{|c|c|c|c|c|c|c|c|c|}
\hline \multirow[t]{2}{*}{ No. } & \multirow{2}{*}{ Barriers } & \multicolumn{5}{|c|}{ Frequency } & \multirow{2}{*}{ Mean } & \multirow{2}{*}{$\begin{array}{l}\text { Std. } \\
\text { dev. }\end{array}$} \\
\hline & & 1 & 2 & 3 & 4 & 5 & & \\
\hline$\overline{\mathrm{B} 1}$ & High initial purchase cost & 3 & 7 & 20 & 29 & 32 & 3.88 & 1.078 \\
\hline B2 & High maintenance cost & 5 & 8 & 17 & 33 & 28 & 3.78 & 1.137 \\
\hline B3 & Lack of solar panel providers & 10 & 9 & 8 & 30 & 34 & 3.76 & 1.337 \\
\hline B4 & $\begin{array}{l}\text { Lack of experienced technicians for } \\
\text { maintenance and support }\end{array}$ & 4 & 12 & 17 & 36 & 22 & 3.66 & 1.112 \\
\hline B5 & Lack of knowledge of financial support & 6 & 13 & 22 & 22 & 28 & 3.58 & 1.241 \\
\hline B6 & Lack of awareness of feed-in-tariff & 9 & 13 & 21 & 24 & 24 & 3.45 & 1.277 \\
\hline B7 & $\begin{array}{l}\text { Lack of knowledge on alternative sources of } \\
\text { electricity generation }\end{array}$ & 4 & 14 & 25 & 36 & 12 & 3.42 & 1.038 \\
\hline B8 & Lack of government incentive programmes & 15 & 12 & 21 & 22 & 21 & 3.24 & 1.378 \\
\hline B9 & Lack of regulations & 8 & 22 & 21 & 23 & 17 & 3.21 & 1.245 \\
\hline $\mathrm{B} 10$ & User conservatism and skepticism & 8 & 23 & 23 & 24 & 13 & 3.12 & 1.194 \\
\hline B11 & Uncertainty of installation cost & 17 & 17 & 23 & 23 & 11 & 2.93 & 1.291 \\
\hline B12 & $\begin{array}{l}\text { Dependence on traditional electricity } \\
\text { generation systems }\end{array}$ & 19 & 31 & 25 & 8 & 8 & 2.51 & 1.171 \\
\hline B13 & Reluctance to innovation & 20 & 35 & 26 & 8 & 2 & 2.31 & 0.980 \\
\hline B14 & $\begin{array}{l}\text { Lack of awareness of solar energy for } \\
\text { electricity }\end{array}$ & 30 & 24 & 24 & 10 & 3 & 2.25 & 1.125 \\
\hline B15 & $\begin{array}{l}\text { Lack of awareness of environmental impact of } \\
\text { fossil fuels }\end{array}$ & 27 & 37 & 13 & 12 & 2 & 2.18 & 1.065 \\
\hline B16 & $\begin{array}{l}\text { Lack of knowledge on electricity generation } \\
\text { systems }\end{array}$ & 26 & 37 & 18 & 7 & 3 & 2.16 & 1.026 \\
\hline B17 & Lack of awareness of solar panels & 41 & 27 & 15 & 3 & 5 & 1.95 & 1.113 \\
\hline
\end{tabular}

Kendall's coefficient of concordance (known as Kendall's $W$ ) was calculated to determine whether different respondents within a group responded in a consistent way or not on the ranking of barriers. Siegel and Castellan (1988) state that the value of $W$ ranges from 0 to 1 and based on the value of $W(0=$ non consensus and $1=$ complete consensus). The value for $W$ for the ranking of the 17 factors was 0.733 , and the level of significance of $W$ was at 0.0 , indicating that significant agreement exists among all of the respondents in a given group regarding the ranking. 


\section{RESULTS OF FACTOR ANALYSIS}

The value of the KMO measure of sampling accuracy is 0.877 , which is higher than 0.5 . The results indicate that the sample set is suitable for FA. Two clusters with eigenvalues greater than 1 were extracted through principal component analysis, accounting for $95 \%$ of the variance. The cluster matrix after quarimax rotation is shown in Table 2. Each of the 10 critical factors belonged to one of the two clusters and the factor loading value exceeded 0.50 . Table 2 also shows that six critical barriers belong to factor 1 and four critical barriers belong to factor 2 . According to the initial interpretation, these two factors are associated with incentives and technology and cost issues. Therefore, factor one was renamed government incentives and technology and factor 2 was renamed cost.

Table 2: Critical factors hindering the use of solar PV systems in Malaysia

\begin{tabular}{llcc}
\hline No. & \multicolumn{1}{c}{ Barriers } & Factor 1 & Factor 2 \\
\hline B10 & User conservatism and skepticism & 0.862 & - \\
B4 & Lack of experienced technicians for maintenance and support & 0.855 & - \\
B8 & Lack of government incentive programmes & 0.855 & - \\
B6 & Lack of awareness of feed-in-tariff & 0.847 & - \\
B3 & Lack of solar panel providers & 0.793 & - \\
B7 & Lack of knowledge on alternative sources of electricity generation & 0.783 & - \\
B1 & High initial purchase cost & - & 0.819 \\
B5 & Lack of knowledge of financial support & - & 0.807 \\
B9 & Lack of regulations & - & 0.805 \\
B2 & High maintenance cost & - & 0.802 \\
\hline
\end{tabular}

\section{FINDINGS AND DISCUSSION}

\section{FACTOR 1}

The "government incentives and technology" factor consists of six critical barriers (see barriers under Factor 1 in Table 2). The six critical barriers under this factor focus on the lack of knowledge on incentives provided by the government and the lack of support to install and maintain solar panels. This factor accounts for $75.5 \%$ of the total variance explained (Table 2). Lack of experienced suppliers of solar panels as well as technicians for support and maintenance clearly reflects that residential users do not have information about where to acquire panels and how to maintain them. This creates uncertainty and negatively impacts the use of solar panels.

In Malaysia, most of the current users of solar panels are industrial buildings or large corporations which have had a large exposure to information about government programmes and technical support. Although residential users know what are solar panels, are aware of the environmental impact of fossil fuels, and are not reluctant to innovation (Table 1), the lack of support is the main barrier for changing the status quo. To a certain extent, the use of solar panels in residential buildings depends on the resources available for dwellings such as low capacity systems and availability of local providers. Residents are not aware of the implications to install solar panels, that is, whether their residences are suitable for installing panels and which measures need to be implemented to ensure their longevity and proper operation. Additionally, the lack of information on incentives such as the FiT and the complicated process for acquiring licenses, results in the residents' tendency to keep using traditional systems for electricity 
generation, that is, a known system rather than a new system that may increase the risks of failure. This situation may explain why "conservatism and skepticism" is one main barrier for the use of solar panels in the Northern region of Malaysia. Therefore, to eliminate technological support and incentives barriers faced by residents, more successful government practices are needed to show the cost benefits of solar panels in Malaysia.

\section{FACTOR 2}

Four critical barriers belong to this factor (see barriers under Factor 2 in Table 2). These factors account for $19.5 \%$ of the total variance explained among all critical factors. Cost is considered a major and sensitive barrier preventing the use of solar panels by most residents in Northern Malaysia. Although the income of respondents is within the average or high range, the financial barrier is a challenge faced by most respondents. These four factors are consistent with the results of previous studies (Hossain et al. 2014; Mekhilef et al. 2011; Tasbirul Islam et al. 2019). The high initial cost involved in solar panels is mainly associated with the required investment to install the system. The solar PV system consists of three components: solar module, inverter, and PV meter. The cost of purchasing a solar PV system is around RM 52,000 to 110,000 (USD 12,556 to 27,100), which includes the FiT application process, system design, installation, and material costs. The survey responses revealed that residents are also concerned with the maintenance costs. Maintenance costs range about RM 300 to 800, which involves cleaning the panels once or twice a year.

Another barrier identified by respondents is related to the lack of regulations and financial support. The expected investment period for a solar PV system is around 20 years. The FiT program allows residents to re-sell the electricity that is not used in their household. However, due to the uncertainty of the market, many service providers of the FiT do not last for 5 to 10 years, thus residents have to find a new provider and make a new contract if the service is terminated. Additionally, the payment rate for the FiT decreases annually by $8 \%$ because more people install solar panels (supply increases) so the government reduces incentives. Given that most residents are mainly concerned with paying the invested cost, the additional risk is also considered a pressure for residents.

The expected economic benefit of solar panels are difficult to achieve in the current market without financial support. Several studies have tried to prove that this higher cost could be offset by resource reductions, loan plans, and broader coverage and technical support for solar panels (Tasbirul Islam et al. 2019). However, if the users cannot receive the monetary benefits, they will not be able to bear the higher cost of solar panels. Some residents mentioned that they do not want to change to solar energy as there are cheaper alternatives available, including coal and gas. Some others mentioned that the government should subsidize the cost of solar panels to reduce the investment cost and promote the technology to a wider range of people. Therefore, to eliminate cost barriers faced by residents, more successful financial management plans are needed to show the cost benefits of solar panels in Malaysia. Effective management by the suppliers can lead to cost savings as well (Muhammad-Sukki et al. 2011). Solar systems have a long lifespan, which is around 30 years. Within this duration, the initial cost can potentially be recovered due to the revenue from the FiT system (Chua and Oh 2011). 


\section{CONCLUSIONS}

This study provides a comprehensive explanation of the status of solar energy PV systems in Malaysia and the barriers to its adoption. This paper contributes to the existing literature by focusing on the perspective of residents, who are the key decision makers regarding the adoption of solar PV systems in residential buildings. A range of barriers to the adoption of solar PV systems are identified and examined using a combination of literature review and a questionnaire survey. The factors inhibiting the adoption of solar PV systems are analysed by using ranking techniques and FA, thus providing a clear understanding of the relationship among these factors. This study ranks the 17 factors based on their relative importance from the perspective of residents. Ten out of the 17 factors are recognized as critical factors and the barriers are categorized into two factors: ( 1 government incentives and technology and (2 cost.

The results also indicate that the most dominant of the five factors pertains to regulations and policies. The government's role in promoting solar PV systems for residential buildings in Northern Malaysia is also highlighted by residents. Residents play the leading role in the adoption of solar PV systems and the survey shows that about $90 \%$ of the residents in Northern Malaysia support innovation and are aware of the environmental impacts of conventional electricity systems. These results are expected to contribute to add information relevant to policy making in the energy sector and the use of solar PV systems. This is a promising start for re-launching the energy programmes in Malaysia. As Malaysia is moving towards sustainable development, an increase in renewable energy use with a whole life cycle perspective needs to start with policies at the local and national level. Policies need to communicate objectives clearly while accompanying that with cost incentives and financial support. This added value, critical in lean thinking can help users, suppliers and the government to achieving efficient performance. For instance, the majority of households have on average 3 to 6 inhabitants so this could be considered for determining the size and capacity of panels. Further investigation with a confirmatory factor analysis and gathering perspectives of the views of residents in other states in Malaysia and a bigger sample should be considered in future research. Other studies could also look at the energy sector of various developing countries where the use of solar PV systems may be an effective way to use available resources to minimize the environmental impact of electricity generation systems.

\section{REFERENCES}

Abdullah, W.S.W., Osman, M., Kadir, M.Z.A., and Verayiah, R. 2019. "The Potential and Status of Renewable Energy Development in Malaysia". Energies, 12(1), 24-37.

Ahmad, S. and Tahar, R. 2014. "Selection of renewable energy sources for sustainable development of electricity generation system using analytic hierarchy process: A case of Malaysia." Renew. Ener., 63(3) 458-466.

Basri, N.A., Ramli, A.T., and Aliyu, A.S. 2015. "Malaysia energy strategy towards sustainability: A panoramic overview of the benefits and challenges". Renew and Sust. Ener. Rev., 42(4) 1094-1105.

Beccali, M., Cellura, M., Guarino, F., Mistretta, M., and Longo, S. 2013. "Eco-design of solar driven systems: a performance comparison between the italian and the brazilian context." Proc. 21th Annual Conference of the International. Group for Lean Construction (IGLC21), Fortaleza, Brazil, 915-924.

Chan, A. P. C., Chan, D. W. M., and Ho, K. S. K. 2003. "Partnering in construction: Critical study of problems for implementation." J. Manage. Eng,19 (3),126-135. 
Chong, C., Ni, W., Ma, L., Lu, P., and Li, Z. 2015. "The Use of Energy in Malaysia: Tracing Energy Flows from Primary Source to End Use”. Energies, 8(4), 2828-2866.

Fit solar plan (FSP) "Fit solar plan- Malaysia: A government project for everyone." $<$ www.fitsolarplan.com> $>$ Feb 7, 2020).

Foo, K.Y. 2015. "A vision on the opportunities, policies and coping strategies for the energy security and green energy development in Malaysia." Renew and Sust. Ener. Rev, 51(2), 1477-1498.

Gadenne, D., Sharma, B., Kerr, T., and Smith, T. (2011). "The influence of Consumers' Environmental Beliefs and Attitudes on Energy Saving Behaviours.” Ener. Pol., 3(12) 7684-7694.

Huovila, P., Koskela, L., 1998. Contribution of the principles of lean construction to meet the challenges of sustainable development. In: Proceedings of the 6th Conference of the International Group of Lean Construction. IGLC), pp. 13-15.

Hossain, F.M., Hasanuzzaman, M., Rahim, M.A., and Ping, H.W. (2014). "Impact of renewable energy on rural electrification in Malaysia: a review". Clean. Tech. Env. Pol., 17(1), 859, 871.

Kadir, M.Z.A.A., Rafeeu, Y., and Adam, N.M. 2010. "Prospective scenarios for the full solar energy development in Malaysia." Renew and Sust. Ener. Rev, 14(9) 3023-3031.

Khor, C. and Lalchand, G. 2014. "A review on sustainable power generation in Malaysia to 2030: Historical perspective, current assessment, and future strategies." Renew. and Sust. Ener. Rev, 29 (1) 952-960.

Mekhilef, S., Safari, A., Mustaffa, W.E.S., Saidur, R., Omar, R., and Younis, M.A.A. (2011). "Solar energy in Malaysia: Current state and prospects." Renew. and Sust. Ener. Rev, 16(1) 386-396.

Muhammad-Sukki, F., Ramirez-Iniguez, R., Abu-Bakar, S.h. McMeeking S.G., and Stewart, B.G. 2011. "An evaluation of the installation of solar photovoltaic in residential houses in Malaysia: Past, present, and future". Ener. Pol., 39 (12) 79757987.

Oh, T., Hasanuzzaman, M.D., Selvaraj, J., Teo, S.C., and Chua, S.C. 2010. "Energy policy and alternative energy in Malaysia: Issues and challenges for sustainable growth". Renew. and Sust. Ener. Rev, 14(4), 1241-1252.

Samsudin, M.S.N., Rahman, M.M., Wahid, A.M. (2016). "Power Generation Sources in Malaysia: Status and Prospects for Sustainable Development." J. of Adv. Rev. on Scie. Res., 25(1) 11-28.

SEDA 2014. Cost Breakdown Solar PV System. <www.seda.gov.my> (Feb 08, 2020).

Shafie, S. M., Mahlia, T.M.I., Masjuki, H.H., and Andriyana, A. (2011). "Current energy usage and sustainable energy in Malaysia: A Review." Renew. and Sust. Ener. Rev, 15(4), 4370-4377.

Siegel, S., and Castellan, N. J. 1988. Nonparametric statistics for the behavioral sciences, McGraw-Hill, New York.

Sustainable Development Goals (SDGs) 2020. <www.sdg.iisd.org/sdgs/. (May 16, 2020).

Tasbirul Islam, M.D., Huda, N., and Saidur, R. 2019. "Current energy mix and technoeconomic analysis of concentrating solar power (CSP) technologies in Malaysia." Renew. Ener., 140 (2) 789-806.

TS-SolarTech 2020. TS-SolarTech. <www.ts-solartech.com > (Feb 08, 2020). 